\title{
In vitro and in vivo activity of meglumine antimoniate produced at Farmanguinhos-Fiocruz, Brazil, against Leishmania (Leishmania) amazonensis, $L$ (L.) chagasi and $L$ (Viannia) braziliensis
}

\author{
Eliane de Morais-Teixeira, Alcione S de Carvalho', Jorge CS da Costa', Silvio L Duarte', \\ Jorge S Mendonça', Núbia Boechat', Ana Rabello/ ${ }^{+}$
}

Laboratório de Pesquisa Clínica, Centro de Pesquisas René Rachou-Fiocruz, Av. Augusto de Lima 1715, 30190-002 Belo Horizonte, MG, Brasil 'Departamento de Síntese Orgânica, Farmanguinhos-Fiocruz, Rio de Janeiro, RJ, Brasil

The leishmanicidal activity of four batches of meglumine antimoniate, produced in Farmanguinhos-Fiocruz, Brazil (TAMs), was assessed and compared to Glucantime ${ }^{\circledR}$-Aventis Pharma Ltda. Using the amastigote-like in vitro model, the active concentrations of $S b^{v}$ varied from $10 \mu \mathrm{g} / \mathrm{ml}$ to $300 \mu \mathrm{g} / \mathrm{ml}$ for L. (L.) chagasi and from $50 \mu \mathrm{g} / \mathrm{ml}$ to $300 \mu \mathrm{g} / \mathrm{ml}$ for L. (L.) amazonensis, with no statistically significant differences among the four batches of TAMs and Glucantime ${ }^{\circledR}$. The inhibitory concentrations $\left(I C_{5}\right)$ determined by the amastigote-infected macrophage model for TAM01/03 and Glucantime ${ }^{\circledR}$ were, respectively: $26.3 \mu \mathrm{g} / \mathrm{ml}$ and $127.6 \mu \mathrm{g} / \mathrm{ml}$ for L. chagasi, $15.4 \mu \mathrm{g} / \mathrm{ml}$ and $22.9 \mu \mathrm{g} / \mathrm{ml}$ for L. amazonensis, and $12.1 \mu \mathrm{g} / \mathrm{ml}$ and $24.2 \mu \mathrm{g} / \mathrm{ml}$ for $\mathrm{L}$. (V.) braziliensis. The activities of the four batches of TAMs were confirmed in an in vivo model by assessing, during eight weeks skin lesions caused by L. braziliensis in hamster that were treated with $20 \mathrm{mg} \mathrm{Sb^{v } / K g / d a y ~ f o r ~} 30$ consecutive days. The meglumine antimoniate produced by Farmanguinhos was as effective as the reference drug, Glucantime ${ }^{\circledR}$-Aventis, against three species of Leishmania that are of medical importance in Brazil.

Key words: leishmaniasis - treatment - meglumine antimoniate - in vitro - in vivo - drug evaluation

The protozoan parasite Leishmania causes a variety of clinical diseases that afflict 12 million people worldwide. Organic salts of pentavalent antimony have been used for the treatment of all clinical forms of leishmaniasis for more than 60 years. Antimonials are thought to act by inhibiting the enzymes of glycolysis and other metabolic pathways (Berman 1988). Two formulations of pentavalent antimonials are currently used: sodium stibogluconate (Pentostam ${ }^{\circledR}$ ) and meglumine antimoniate (Glucantime ${ }^{\circledR}$ ). Both treatments are given intravenously or intramuscularly and demonstrate similar efficacy when used in equivalent doses.

The Brazilian Ministry of Health recommends a oncedaily injection of $20 \mathrm{mg} \mathrm{Sb}^{\mathrm{v}} / \mathrm{Kg}$ for 20 to 40 days for the treatment of visceral leishmaniasis (VL) and $15 \mathrm{mg} / \mathrm{Kg} /$ day for 20 days for the treatment of cutaneous leishmaniasis (MS 2006a, b). The cost per treatment, including delivery and clinical monitoring, reaches approximately US\$ 200 . This is a relatively high expenditure for public health as about 38,000 patients are treated yearly. The cost of Glucantime ${ }^{\circledR}$ is about US\$80, depending on the clinical form and schedule. Cheaper generic formulations of sodium stibogluconate have recently become available. Studies conducted in the Sudan, Kenya, Ethiopia, Bolivia, and Colombia showed that generic sodium stibogluconate (Albert David Ltd, Calcutta, India) was

Financial support: CNPq, Fapemig

+ Corresponding author: ana@cpqrr.fiocruz.br

Received: 18 February 2008

Accepted: 10 June 2008 equivalent to Pentostam ${ }^{\circledR}$ and Glucantime ${ }^{\circledR}$ for the treatment of leishmaniasis in terms of both safety and efficacy (Veeken et al. 2000, Moore et al. 2001, Ritmeijer et al. 2001, Soto et al. 2004, Bermúdez et al. 2006). The reported cost of the generic pentavalent antimony stibogluconate is approximately $7 \%$ that of Pentostam ${ }^{\circledR}$ ( US\$ 13/treatment; Ritmeijer et al. 2001), and 20\% that of meglumine antimoniate in the form of Glucantime ${ }^{\circledR}$ (Soto et al. 2004).

In 2002, due to the menace of an unsupplied market of meglumine antimoniate, Farmanguinhos-Fiocruz (TAMs), a pharmaceutical company that belongs to the Brazilian Ministry of Health, developed an alternative process to produce this API (Active Pharmaceutical Ingredient) in its R\&D laboratory. This study presents the evaluation of the activity of the TAMs against the Leishmania species of medical importance in Brazil, compared to the reference drug, Glucantime ${ }^{\circledR}$-Aventis Pharma.

\section{MATERIALS AND METHODS}

The leishmanicidal activities of four batches of TAMs were assessed and compared to Glucantime ${ }^{\circledR}$ Aventis using the amastigote-like in vitro model. Next, the inhibitory concentration $\left(\mathrm{IC}_{50}\right)$ of one of the batches of meglumine antimoniate (TAM 01/03-Farmanguinhos) was determined using the amastigote-infected macrophage model. Additionally, an in vivo study was conducted to evaluate the efficacy of the four batches of TAMs against L. (Viannia) braziliensis.

Drugs - Four batches of TAMs were prepared in the R\&D laboratories of Farmanguinhos-Fiocruz, Rio de Janeiro, Brazil (batches: TAM 01/03, TAM 02/03, TAM 
03/03 and TAM 021/02) according to Gailliot (1941). An alternative one-pot procedure was employed, and synthesis was initiated using N-methylglucamine (USP CAS 6.284-40-8 Spectrum Chemical Mfg. Corp. USA, lot PG 0147) in aqueous diethyl-amine in the presence of antimony pentachloride (Chemical \& Metal Industries, Inc, USA). The target compound was then precipitated after addition of sufficient ethanol to the reactor (Bar-

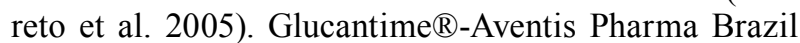
$\left(300 \mathrm{mg} / \mathrm{ml}, 81 \mathrm{mg} / \mathrm{ml} \mathrm{Sb}^{\mathrm{v}}\right.$-batch 300063$)$ and Amphotericin B (AmB) deoxycholate (Fungizone ${ }^{\circledR}$-Bristol-Meyers Squibb Pharmaceutics Ltda, Bedford, USA) were used as reference and control drugs, respectively.

For the in vitro assays, the four batches of TAMs were suspended in deionized water at $80^{\circ} \mathrm{C}$ and sterilized by passage through $0.2 \mu \mathrm{m}$ membrane filters. AmB was reconstituted by rapidly adding $10 \mathrm{ml}$ of water into the lyophilized cake and shaking the vial until the colloidal suspension became clear, as per the manufacturer's instructions. All subsequent dilutions were prepared in fresh RPMI 1640 (Sigma-Aldrich, St. Louis, USA) culture medium on the day of the assay. Glucantime $\AA$ and TAMs were stored at room temperature in the dark until use. $\mathrm{AmB}$ was maintained at $2-8^{\circ} \mathrm{C}$ and was used for a maximum of 30 days (manufacturer's instructions).

Parasites and cultivation of amastigote-like forms Leishmania (Leishmania) chagasi strain $\mathrm{MHOM} / \mathrm{BR} / 70 /$ BH46,L.(Leishmania) amazonensis strain IFLA/BR/1967/ $\mathrm{PH}-8$, and L. braziliensis strain WHO-MHOM/BR/75/ M2903 were used throughout the study. The strains were maintained by successive passages in golden hamsters (Mesocricetus auratus) and amastigotes were harvested from spleen (L. chagasi) or skin lesions (L. amazonensis and $L$. braziliensis) of infected animals.

Amastigote-like forms were transformed from stationary-phase promastigotes cultivated in Schneider's insect medium (SIGMA-ALDRICH, St. Louis, USA) supplemented with $10 \%$ heat-inactivated fetal calf serum (FCS; GIBCO, Grand Island, USA) at $\mathrm{pH} 7.2,26^{\circ} \mathrm{C}$. Promastigotes were centrifuged (10 min/1000 g), resuspended in Schneider's medium, and transformed into amastigote-like forms according to Teixeira el al. (2002), with modifications: $L$. chagasi, $35^{\circ} \mathrm{C}, \mathrm{pH} 7.2,10 \% \mathrm{FCS}$, for 6 days; $L$. amazonensis, $32^{\circ} \mathrm{C}, \mathrm{pH} 6.0,5 \% \mathrm{FCS}$, for 7 days; and $L$. braziliensis, $32^{\circ} \mathrm{C}$, pH $6.0,5 \% \mathrm{FCS}$, for 5 days. These parameters yielded the highest transformation rates as assessed by previous comparisons using different culturing conditions for each species (data not shown).

Amastigote-like model for L. chagasi and L. amazonensis - The leishmanicidal activities of the four batches of TAMs were tested by using the amastigote-like model. The amastigote-like forms were added to the Schneider's medium in concentrations of $5 \times 10^{7} / \mathrm{ml}$ for $L$. chagasi, and $2 \times 10^{7} / \mathrm{ml}$ for $L$. amazonensis and incubated with TAM 01/03, TAM 02/03, TAM 03/03, TAM 021/02 and Glucantime $\mathbb{R}$ (concentrations of Sbv $: 5,10,50,150$ and $300 \mu \mathrm{g} / \mathrm{ml}$ ) and AmB $(0.2 \mu \mathrm{g} / \mathrm{ml})$. Samples were seeded into 96-well flat-bottom microtrays, in triplicate, and were incubated at $35^{\circ} \mathrm{C}$ or $32^{\circ} \mathrm{C}$. After $72 \mathrm{~h}$, parasites were counted using a Neubauer ${ }^{\mathrm{TM}}$ chamber. Three independent experiments were performed in triplicate on different days. The number of parasites counted in wells without drug was set as $100 \%$ parasite survival (parasite controls).

Amastigote-macrophage assay for L. chagasi, L. amazonensis, and L. braziliensis - Balb/c mice were injected intraperitoneally with $1.5 \mathrm{ml}$ of $3 \%$ tioglicolate medium (Biobrás, Brazil). After $96 \mathrm{~h}$, the peritoneal macrophages were harvested by peritoneal lavage using cold RPMI-1640 medium. Cells were counted, centrifuged, and resuspended at a concentration of $4 \times 10^{5} / \mathrm{ml}$ in RPMI-1640 medium without supplements. Sterile round glass coverslips $(13 \mathrm{~mm})$ were placed in each well of 24-well culture plates. Macrophages were pipetted in a volume of $500 \mu \mathrm{l} /$ well and allowed to attach to the coverslips for $2 \mathrm{~h}$ at $37^{\circ} \mathrm{C}$ in $5 \% \mathrm{CO}_{2}$. After $2 \mathrm{~h}$, the medium was removed from the wells and replaced with $500 \mu 1$ of warm $\left(37^{\circ} \mathrm{C}\right)$ RPMI containing $10 \%$ FCS and penicillin $(50 \mathrm{U} / \mathrm{ml})$ and streptomycin $(50 \mu \mathrm{g} / \mathrm{ml})$. The following day, a suspension of $4 \times 10^{6}$ amastigote-like L. chagasi, L. amazonensis, or L. braziliensis was added to each well in $500 \mu \mathrm{l}$ of RPMI (macrophage:parasite ratio of 1:10). The plates were incubated for $4 \mathrm{~h}$ at $37^{\circ} \mathrm{C}$ in $5 \% \mathrm{CO}_{2}$, and the medium was aspirated to remove free-floating parasites. Fresh RPMI $(1 \mathrm{ml})$ with or without the drugs TAM $01 / 03$, Glucantime $\AA$, or $A m B(0.2 \mu \mathrm{g} / \mathrm{ml})$ at the appropriate concentration of $\mathrm{Sb}^{\mathrm{v}}(250 \mu \mathrm{g}$ to $7.8 \mu \mathrm{g}$ for L. chagasi and $40 \mu \mathrm{g}$ to $1.2 \mu \mathrm{g}$ for L. amazonensis and $L$. braziliensis) was added to wells in triplicate. The plates were incubated for $72 \mathrm{~h}$ at $37^{\circ} \mathrm{C}$ in $5 \% \mathrm{CO}_{2}$. The medium was aspirated and the coverslips were removed, air-dried, and glued to microscope slides. After staining with Giemsa, the cells were counted. The assays were considered valid if at least $80 \%$ of the macrophages in the control wells were infected. Three independent experiments in triplicate were performed for each concentration to determine the meglumine antimoniate efficacy. The results are presented as the ratio of infected (number of amastigotes) proportions between treated and non-treated macrophage cultures.

In vivo evaluation: golden hamster model for L. braziliensis - WHO-MHOM/BR/75/M2903 L. braziliensis was isolated from fragments of cutaneous lesions present in the paws of previously infected hamsters. The fragments were excised, macerated in saline solution, and quantified in a Neubauer ${ }^{\mathrm{TM}}$ chamber. Fifty-four male hamsters, weighing 100 to $110 \mathrm{~g}$, were infected with L. braziliensis amastigotes $\left(8 \times 10^{5} / 100 \mu \mathrm{l}\right)$ by subcutaneous injection in the hind footpad. Treatment by intramuscular injection of each formulation of TAMs (20 $\mathrm{mg} \mathrm{Sb} / \mathrm{kg} /$ day) was initiated five days after infection and was given over the course of 30 consecutive days as follows: TAM 01/03 (group B), TAM 02/03 (group C), TAM 03/03 (group D), TAM 021/02 (group E), Glucantime ${ }^{\circledR}$ (drug-reference group F). Group A is the untreated control group, which received intramuscular injections of distilled sterile water. The lesions were examined weekly for eight weeks by measuring the size of the infected footpad with a vernier caliper. The animals were euthanized 30 days after the end of the treatment. 
Data analysis - The data were processed using MINITAB V. 13.1 or Graph Prism 4 software. The active drug concentrations were compared by analysis of variance (ANOVA) or Kruskal-Wallis tests, depending on the distribution of the variables and paired comparisons done by the Dunn's or Tukey tests. $\mathrm{IC}_{50}$ values were calculated by linear regression analysis (MINITAB V. 13.1) or linear interpolation (Microsoft Office Excel 2003) (Huber \& Koella 1993). Linear regression was used when the distribution was normal (parametric method) and linear interpolation (non-parametric) was applied when the distribution was not normal.

Ethics - Animals were handled according to local and federal regulations, and the research protocols were approved by the Fiocruz Committee on Animal Research (protocol P-0321/06; licence L-0024/8).

\section{RESULTS}

Activity of the four batches of TAMs using the amastigote-like model - The leishmanicidal activities against amastigote-like forms of L. chagasi and L. amazonensis of the four batches of TAMs, as well as meglumine antimoniate, Glucantime ${ }^{\circledR}$-Aventis, AmB, and the control, are shown in Fig. 1. Activity was detected for concentrations that varied from $10 \mu \mathrm{g} / \mathrm{ml}$ to $300 \mu \mathrm{g} / \mathrm{ml}$ for $L$. chagasi (Fig. 1A) and from $50 \mu \mathrm{g} / \mathrm{ml}$ to $300 \mu \mathrm{g} / \mathrm{ml}$ for $L$. amazonensis (Fig. 1B). No statistically significant differences were observed among the four batches of TAMs at any concentration. The mean value of parasite inhibition observed with the control drug $(0.2 \mu \mathrm{g} / \mathrm{ml} \mathrm{AmB})$ was $94.6 \%$ for $L$. chagasi and $80 \%$ for $L$. amazonensis.

Activity of TAMs using the amastigote-infected macrophage model - Peritoneal macrophages infected with amastigote-like forms of L. chagasi, L. amazonensis, and $L$. braziliensis were treated with different concentrations of Glucantime ${ }^{\circledR}$ and one batch of TAMs: TAM $01 / 03$. The Table summarizes the comparative inhibitory concentrations.

In the amastigote intracellular assay of L. chagasi, the $\mathrm{IC}_{50}$ was $26.3 \mu \mathrm{g} / \mathrm{ml}$ for TAM $01 / 03$ and $127.6 \mu \mathrm{g} / \mathrm{ml}$

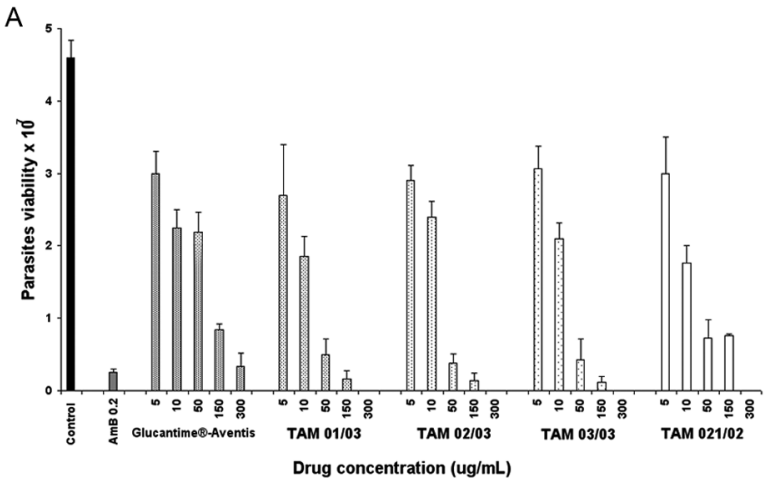

$(\mathrm{CI}=106.7-148.9 \mu \mathrm{g} / \mathrm{ml})$ for Glucantime ${ }^{\circledR}$, respectively, as determined by linear interpolation and linear regression $\left(\mathrm{r}^{2}=75.8 \%\right)$. These $\mathrm{IC}_{50}$ values were statistically different $(\mathrm{p}=0.0000)$, with the $\mathrm{IC}_{50}$ of TAM 01/03 lower than that observed for Glucantime ${ }^{\circledR}$. The IC ${ }_{50}$ values of $15.4 \mu \mathrm{g} / \mathrm{ml}(\mathrm{CI}=10.1-20.7 \mu \mathrm{g} / \mathrm{ml})$ for TAM $01 / 03$ and $22.9 \mu \mathrm{g} / \mathrm{ml}(\mathrm{CI}=18.2-27.5 \mu \mathrm{g} / \mathrm{ml})$ for Glucantime ${ }^{\circledR}$ for the activity against intracellular amastigotes of L. amazonensis, were determined by linear regression $\left(\mathrm{r}^{2}=67.0 \%\right.$ and $\left.83.7 \%\right)$. No statistical difference was observed between these $\mathrm{IC}_{50}$ values $(\mathrm{p}=0.092)$. The $\mathrm{IC}_{50}$ values for $L$. braziliensis were $12.1 \mu \mathrm{g} / \mathrm{ml}(\mathrm{CI}=8.6-$ $15.6 \mu \mathrm{g} / \mathrm{ml})$ for TAM $01 / 03$ and $24.2 \mu \mathrm{g} / \mathrm{ml}(\mathrm{CI}=21.1$ $27.4 \mu \mathrm{g} / \mathrm{ml}$ ) for Glucantime ${ }^{\circledR}$, both of which were estimated by linear regression $\left(r^{2}=85.3 \%\right.$ and $\left.92.9 \%\right)$. These values were statistically different $(\mathrm{p}=0.021)$, with the lower $\mathrm{IC}_{50}$ value for TAM 01/03.

Comparison of the $\mathrm{IC}_{50}$ of Glucantime ${ }^{\circledR}$-Aventis among Leishmania species showed statistical differences between $L$. chagasi and L. amazonensis $(\mathrm{p}<0.01)$, and $L$. chagasi and $L$. braziliensis $(\mathrm{p}<0.01)$. The values were not statistically different $(\mathrm{p}>0.05)$ between L. amazonensis and L. braziliensis. In contrast, the $\mathrm{IC}_{50}$ of $\mathrm{TAM} 01 / 03$ were similar $(\mathrm{p}=0.368)$ among the studied species. The mean value of parasite inhibition observed with the control drug $(0.2 \mu \mathrm{g} / \mathrm{ml} \mathrm{AmB})$ was $99.7 \%$ for L. chagasi, $99.5 \%$ for L. amazonensis, and $98 \%$ for L. braziliensis.

In vivo activity of TAMs and Glucantime ${ }^{\circledR}$-Aventis against L. braziliensis - Hamsters were infected with an amastigote suspension of $L$. braziliensis and treated with $20 \mathrm{mg} \mathrm{Sb} / \mathrm{Kg} /$ day of the four batches of TAMs or Glucantime ${ }^{\circledR}$ beginning at five days post-infection and continued for 30 consecutive days. The progress of the lesions was assessed weekly for eight weeks (Fig. 2). Nodes were observed in the footpads of the animals five days after infection (before treatment), and no statistically significant difference was observed among the node size of the groups $(p=0.854)$. After seven days of treatment, skin lesions remained similar among the groups $(p=0.056)$. Fourteen days after treatment initiation,

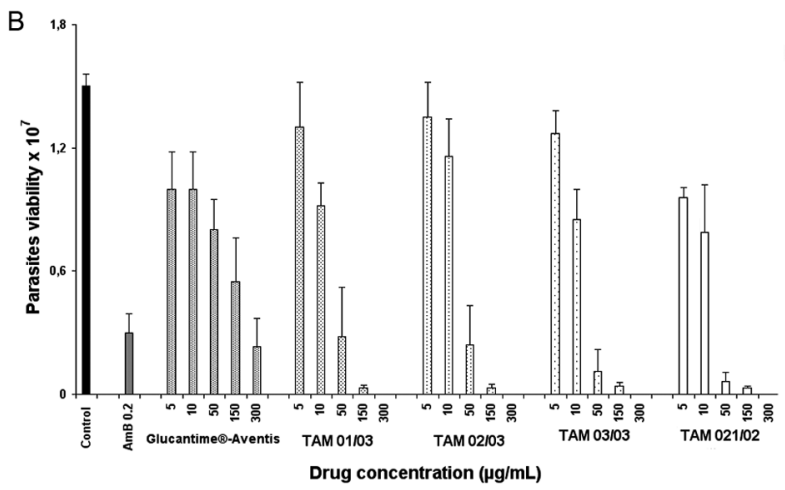

Fig. 1: activity of meglumine antimoniate Glucantime ${ }^{\circledR}$-Aventis and the four batches from Farmanguinhos (TAM 01/03, TAM 02/03, TAM $03 / 03$ and TAM 021/02) against amastigote-like forms of L. chagasi (A) and L. amazonensis (B). Amphotericin B (AmB) was used as the reference control drug. Values represent the mean $\pm \mathrm{SD}$ of three repeated experiments, each performed in triplicate. Significant differences for $L$. chagasi were observed at $10 \mu \mathrm{g} / \mathrm{ml}$ : control versus Gluc ${ }^{\circledR}$ and TAMs $(\mathrm{p}<0.05) ; 50 \mu \mathrm{g} / \mathrm{ml}$ and $150 \mu \mathrm{g} / \mathrm{ml}$ : control versus Gluc ${ }^{\circledR}$, Gluc ${ }^{\circledR}$ and TAMs ( $\mathrm{p}<0.01) ; 300 \mu \mathrm{g} / \mathrm{ml}$ : control x Gluc ${ }^{\circledR}(\mathrm{p}<0.01)$. For L. amazonensis, $50 \mu \mathrm{g} / \mathrm{ml}$ : control versus Gluc ${ }^{\circ}$ and TAMs $(\mathrm{p}<0.05) ; 150 \mu \mathrm{g} / \mathrm{ml}$ : control versus Gluc ${ }^{\circledR}$ and TAMs $(\mathrm{p}<0.01) ; 300 \mu \mathrm{g} / \mathrm{ml}$ : control versus Gluc ${ }^{\circledR}(\mathrm{p}<0.01)$. 
TABLE

Inhibitory concentrations $\left(\mathrm{IC}_{50}\right)$ of Glucantime and meglumine antimoniate produced at Farmanguinhos-Fiocruz TAM 01/03 against intracellular amastigote of three Leishmania species

\begin{tabular}{lccc}
\hline & \multicolumn{2}{c}{$\mathrm{IC}_{50}-\mu \mathrm{g} / \mathrm{ml}(\mathrm{CI})^{a}$} & p value \\
\cline { 2 - 3 } Parasite & Glucantime ${ }^{a}-$ Aventis & TAM 01/03 & 0.000 \\
L. $($ L.) chagasi & $127.6(106.2-148.9)$ & $26.3^{b}$ & 0.092 \\
L. (L.) amazonensis & $22.9(18.2-27.5)$ & $15.4(10.1-20.7)$ & 0.021 \\
L. $($ V.) braziliensis & $24.2(21.1-27.4)$ & $12.1(8.6-15.6)$ & \\
\hline
\end{tabular}

$a$ : confiance interval; $b$ : $\mathrm{IC}_{50}$ determinated by linear interpolation.

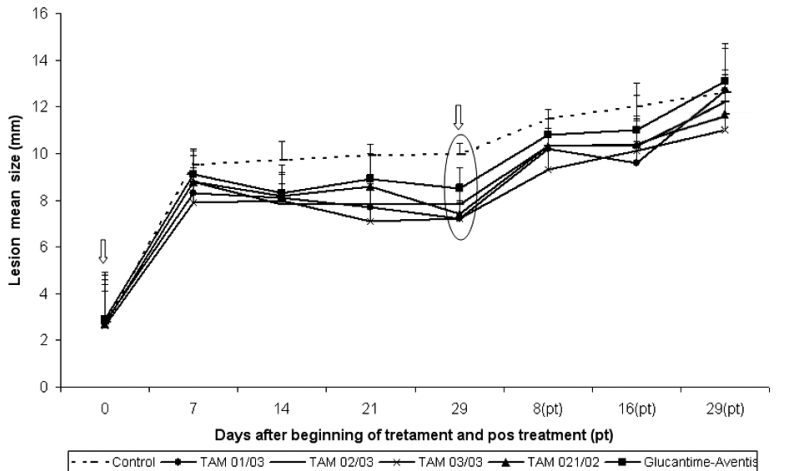

Fig. 2: evaluation of the activity of meglumine antimoniate in male golden hamsters infected with L. braziliensis. Animals were treated vial intramuscular with $20 \mathrm{mg} \mathrm{Sb} / \mathrm{Kg} /$ day of meglumine antimoniate (Glucantime ${ }^{\circledR}$-Aventis and TAMs-Farmanguinhos) for 30 days. Vertical bars represent the average and standard error of lesion size (diameter) for each group. The arrows indicate the start and end of treatment. The ellipse indicates the maximum activity between the treatment-groups and the control. No statistical differences were observed between the four batches of meglumine antimoniate produced at Farmanguinhos and the reference drug Glucantime ${ }^{\circledR}$.

however, the lesions became thicker in the group of untreated hamsters compared with the group that received TAM 02/03 ( $<<0.01)$ or TAM 03/03 ( $<<0.05)$. No statistical differences were observed among the four batches of TAMs or between each TAM and Glucantime ${ }^{\circledR}$. This trend persisted for 29 days after the beginning of treatment, when the lesions were significantly larger in the untreated group compared to all treated-groups (TAM $01 / 03, \mathrm{p}=0.0000$; TAM 02/03, $\mathrm{p}=0.0002$; TAM 03/03, $\mathrm{p}=0.0000$; TAM 021/02, $\mathrm{p}=0.0000$; Glucantime $\mathbb{R}$, $\mathrm{p}=0.0298$ ). The lesions of all groups worsened after treatment end. Statistical differences were still significant between the untreated group and TAM 01/03 and TAM 03/03 at eight and 16 days after treatment ended $(p<0.05 ; p=0.0036$ and $p=0.0357 ; p=0.0357$, respectively). At 29 days after the end of treatment, lesions had increased in all groups, but the differences among groups were not significant $(\mathrm{p}=0.157)$.

\section{DISCUSSION}

Despite their toxicity, pentavalent antimonials $\left(\mathrm{Sb}^{\mathrm{v}}\right)$ in the form of sodium stibogluconate (Pentostam $\AA$ ) and meglumine antimoniate (Glucantime $($ ) remain the drugs of choice for the treatment of leishmaniasis in many countries, mainly due to their effectiveness and relatively low cost compared with the therapeutic alternatives currently available.

In this work, the in vitro and in vivo activity of the TAMs was assessed and compared to the reference drug Glucantime ${ }^{\circledR}$-Aventis. Due to the simplicity of the amastigote-like assay and the avoidance of animals use, this model was chosen for the initial testing and screening. As this model showed that the four batches have similar in vitro activity, only one of the batches (TAM 01/03) was tested in the macrophage assay to determine the $\mathrm{IC}_{50}$. Moreover, for the three species tested, the $\mathrm{IC}_{50}$ remained below the dose that was toxic for macrophages, which was determined to be higher than $300 \mu \mathrm{g} / \mathrm{ml}$ for each of the four batches (data not shown).

Alternative generic drugs for the treatment of neglected diseases are tactical for the disease control programs. The price and sustainability of drug production are key points that may hinder control strategies or, even worse, risk the lives of patients. Nevertheless, the quality of the drug production needs to be carefully assessed. It is important to note that the activity obtained with the four batches of the TAMs was reproducible, as interbatch variation is one important shortcoming associated with antimoniate production.

The threat of antimoniate to the lives of patients has been experienced in different countries. In 2000, the Brazilian Ministry of Health received notification from public health care centers of the high frequency of side effects reported by patients receiving meglumine antimoniate produced by Eurofarma (registered as similar to the reference product at the National Regulatory Agency - Agência Nacional de Vigilância Sanitária - ANVISA). The epidemiological and the clinical investigation led to physical chemistry analysis of the batches, which resulted in the detection of heavy metals (Silva Junior 2001). The higher frequency of skin reactions in patients was attributed to the presence of heavy metals (Romero et al. 2003).

In Nepal, fatal cardiotoxicity occurred among VL patients treated with a batch of generic sodium stibogluconate from GL Pharmaceuticals, Calcutta, India. These instances are in contrast with the low total death rate and the low death rate due to cardiotoxicity observed among patients treated with generic sodium stibogluconate from Albert David Ltd (Rijal et al. 2003).

Our in vitro and in vivo results showed that the TAMs was as active as the reference drug Glucantime $\AA$-Aventis against species of Leishmania of medical importance in 
Brazil. Further steps are required to complete the generic drug development. The most challenging issue is to achieve a stable formulation as described by Cabral et al. (2008), which developed formulations of meglumine antimoniate with higher stability regarding the increase in $\mathrm{Sb}^{\mathrm{III}}$ percentage. Quality control of produced batches, chemical analysis, and bioequivalence studies would then suffice to recommend the adoption of the generic product as a low cost alternative to the branded reference drug. A clinical study addressing efficacy and safety would complement the current study.

\section{REFERENCES}

Barreto Jr AC, Estevão LRM, Biscaia Jr EC, de Carvalho AS, Duarte SL, Costa JCS, Souza MVN, de Mendonca JS, da Silva JFC 2005. Evaluating the effect of the antimonium pentachloride feed rate to ensure safer conditions during the synthesis of meglumine antimoniate. Ind Eng Chem Res 44: 6578-6582.

Berman JD 1988. Chemotherapy for leishmaniasis: biochemical mechanisms, clinical efficacy, and future strategies. Rev Infec Dis 10: 560-586.

Bermúdez H, Rojas E, Garcia L, Desjeux P, Dujardin JC, Boelaert M, Chappuis F 2006. Generic sodium stibogluconate is as safe and effective as branded meglumine antimoniate, for the treatment of tegumentary leishmaniasis in Isiboro Secure Park, Bolívia. Ann Trop Med Parasitol 100: 591-600.

Cabral LM, Juliano VNM, Dias LRS, Dornelas CB, Rodrigues CR, Villardi M, Castro HC, Santos TC 2008. Speciation of antimony (III) and antimony (V) using hybride generation for meglumine antimoniate pharmaceutical formulations quality control. $\mathrm{Mem}$ Inst Oswaldo Cruz 103: 130-137.

Gailliot PL 1941. Process for the manufacture of new organic antimony compounds. (Societé des usines chimiques de Rhone-Poulenc). GB Patent 533-354.

Huber W, Koella JC 1993. A comparison of three methods of estimating $\mathrm{EC}_{50}$ in studies of drugs resistance of malaria parasites. Acta Trop 55: 257-261.

Moore E, O’Flaherty D, Heuvelmans H, Seaman J, Veeken H, de Wit
S, Davidson R 2001. Comparison of generic and proprietary sodium stibogluconate for the treatment of visceral leishmaniasis in Kenya. Bull World Health Organ 79: 388-393.

MS - Ministério da Saúde 2006a. Atlas de Leishmaniose Tegumentar Americana: diagnóstico clínico e diferencial. Secretaria de Vigilância e Saúde, Departamento de Vigilância Epidemiológica, Brasília, Editora MS, 136 pp.

MS - Ministério da Saúde 2006b. Manual de Vigilância e Controle da Leishmaniose Visceral, Secretaria de Vigilância e Saúde, Departamento de Vigilância Epidemiológica, Brasília, Editora MS, 120 pp.

Rijal S, Chappuis F, Singh R, Boelaert M, Loutan L, Koirala S 2003. Sodium stibogluconate cardiotoxicity and safety of generics. Trans R Soc Trop Med Hyg 97: 597-598.

Ritmeijer K, Veeken H, Melaku Y, Leal G, Amsalu R, Seaman J, Davidson RN 2001. Ethiopian visceral leishmaniasis: generic and proprietary sodium stibogluconate are equivalent. HIV coinfected patients have a poor outcome. Trans $R$ Soc Trop Med Hyg 95: 668-672.

Romero GAS, Flores EMM, Noronha EF, Macedo VO 2003. High frequency of skin reactions in patients with leishmaniasis treated with meglumine antimoniate contaminated with heavy metals. A comparative approach using historial controls. Mem Inst Oswaldo Cruz 98: 145-149.

Silva Junior JB 2001. Antimoniato de meglumina. Relatório técnico. Brasília: CENEPI/FUNASA 2000. Rev Soc Bras Med Trop 34: 103-105.

Soto J, Valda-Rodriquez L, Toledo J, Vera-Navarro L, Luz M, Monastérios-Torrico H, Veja J, Berman J 2004. Comparison of generic branded pentavalent antimony for treatment of new world cutaneous leishmaniasis. Am J Trop Med Hyg 71: 577-581.

Teixeira MCA, Santos RJ, Sampaio RB, Pontes-de-Carvalho L, dos Santos WLC 2002. A simple and reproducible method to obtain large numbers of axenic amastigotes of different Leishmania species. Parasitol Res 88: 963-968.

Veeken H, Ritmeijer K, Seaman J, Davidson R 2000. A randomized comparison of branded sodium stibogluconate and generic sodium stibogluconate for the treatment of visceral leishmaniasis under field conditions in Sudan. Trop Med Int Health 5: 312-317. 